\title{
Systematic research on the effect of both positive and negative mismatch dopants in double-doped YBCO superconducting films
}

Xu, Yan; Suo, Hongli; Qureishy, Thomas; Grivel, Jean-Claude; Mikheenko, Pavlo; Liu, Min; Ma, Lin; Zhang, Xiaolong; Zhou, Yuqi; Liu, Jianhua

Total number of authors:

13

Published in:

Journal of the European Ceramic Society

Link to article, DOI:

10.1016/j.jeurceramsoc.2020.07.074

Publication date:

2021

Document Version

Early version, also known as pre-print

Link back to DTU Orbit

Citation (APA):

Xu, Y., Suo, H., Qureishy, T., Grivel, J-C., Mikheenko, P., Liu, M., Ma, L., Zhang, X., Zhou, Y., Liu, J., Wang, L., Zhang, Z., \& Wang, Q. (2021). Systematic research on the effect of both positive and negative mismatch dopants in double-doped YBCO superconducting films. Journal of the European Ceramic Society, 41(1), 480487. https://doi.org/10.1016/j.jeurceramsoc.2020.07.074

\section{General rights}

Copyright and moral rights for the publications made accessible in the public portal are retained by the authors and/or other copyright owners and it is a condition of accessing publications that users recognise and abide by the legal requirements associated with these rights.

- Users may download and print one copy of any publication from the public portal for the purpose of private study or research.

- You may not further distribute the material or use it for any profit-making activity or commercial gain

- You may freely distribute the URL identifying the publication in the public portal 


\title{
Systematic research on the effect of both positive and negative mismatch dopants in double-doped YBCO superconducting films
}

\author{
Yan Xu ${ }^{a, b}$, Hong-Li Suo *a, Thomas Qureishy ${ }^{c}$, Jean-Claude Grivel ${ }^{b}$, Pavlo \\ Mikheenko ${ }^{c}$, Lin Ma ${ }^{a}$, Min Liu $^{a}$, Xiaolong Zhang ${ }^{a}$, Yuqi Zhou ${ }^{a}$, Jianhua Liu ${ }^{d}$, Lei \\ Wang $^{d}$, Zili Zhang ${ }^{* d}$, Qiuliang Wang ${ }^{d, e}$
}

a. Beijing University of Technology, Beijing 100124, China.

b. Technical University of Denmark, 2800 Kgs Lyngby, Denmark.

c. Department of Physics, University of Oslo, P. O. Box 1048 Blindern, 0316 Oslo, Norway

d. Institute of Electrical Engineering, Chinese Academy of Sciences, Beijing 100190, China

e. University of Chinese Academy of Sciences, Beijing 100049, China;

\section{ABSTRACT}

We report a novel doping strategy for $\mathrm{YBa}_{2} \mathrm{Cu}_{3} \mathrm{O}_{7-\mathrm{x}}(\mathrm{YBCO})$ superconducting films by using a positive mismatch, $\mathrm{Ba}_{2} \mathrm{YNbO}_{6}(\mathrm{BYNO})$, and a negative mismatch, $\mathrm{LaAlO}_{3}$ (LAO), imultaneously. Double doping can significantly reduce the $c$-strain in the YBCO film by canceling the strain between the two dopants. By systematically optimizing the doping amount of both BYNO and LAO, it was found that BYNO and LAO do not act equally. The microstructure and distribution of both BYNO and LAO were investigated with magneto-optic microscopy and scanning electron microscopy. The effect of BYNO and LAO on pinning was confirmed. The results of this study 
will help select appropriate positive mismatch and negative mismatch dopants, which is fundamental to the design and fabrication of pinning centers to fit different application scenarios.

\section{INTRODUCTION}

$\mathrm{REBa}_{2} \mathrm{Cu}_{3} \mathrm{O}_{7-\mathrm{x}}(\mathrm{REBCO})$ superconductors have been widely used in multiple fields, including motors [1], generators [2], cables [3], Superconducting magnetic energy storage (SMES)[4], current limiters [5], transformers [6], and current leads [7]. Moreover, REBCO is one of the most abundant superconductor materials of insert coils for extremely high-field user magnets. Multiple whole superconductor high magnetic field magnets have been fabricated, such as 30.5 $\mathrm{T}$ in RIKEN [8], $26.4 \mathrm{~T}$ in SuNAM [9], and 32 T, at the National High Magnetic Field Laboratory (Maglab) [10]. In 2019, our group at the Institute of Electrical Engineering, Chinese Academy of Sciences (IEE CAS) successfully fabricated a $32.35 \mathrm{~T}$ instrument by using REBCO as the insert coil, which is the world record highest magnetic field value of whole superconductor magnet [11].

The REBCO tape must have different properties to fit the requirements of diverse application scenarios, which has attracted considerable research [12-7]. The artificial pinning center (APC) has proved to be the most effective method to improve the superconducting properties of REBCO materials. Multiple compounds have been investigated, including $\mathrm{BaZrO}_{3}$ (BZO) [18], $\mathrm{BaHfO}_{3}$ (BHO) [19], $\mathrm{BaSnO}_{3}$ (BSO) [20], $\mathrm{Ba}_{2} \mathrm{YNbO}_{6}$ (BYNO) [21], $\mathrm{Ba}_{2} \mathrm{YTaO}_{6}$ (BYTO) [22], and $\mathrm{Ba}_{2} \mathrm{Y}(\mathrm{Nb}, \mathrm{Ta}) \mathrm{O}_{6}$ (BYNTO) 
[23]. However, the suitability of each type of APC or dopant for different applications is not yet clear. In 2017, McManus-Driscoll published a review paper on APCs, which includes a systematic survey of studies on the pinning centers for different application scenarios [24]. Therein four different kinds of APCs are discussed: 3D, 2D, 1D, and 0D. The 1D and 2D APCs are used in high-temperature and low-field scenarios, such as cables, current limiters, and transformers, while the 3D and 0D APCs are more suitable for low-temperature and high-field scenarios, such as magnets.

The review of McManus-Driscoll focused on the pulsed laser deposition (PLD) method. However, in the metal-organic deposition (MOD) method, it is difficult to obtain a $1 \mathrm{D}$ or $2 \mathrm{D}$ APC due to the reaction mechanism of the method. Most pinning centers are either 3D or $0 \mathrm{D}$, which are voids and secondary phases or tiny defects, such as vacancies and substitutional atoms, respectively [13]. Along with the pinning effect of the dopant, a large nanostrain is also present [24]. The pinning force can be improved by increasing the dopant amount. However, the associated large strain can cause macro-level defects such as cracks in the film, which result in severe deterioration of the superconducting properties. Normally, the doping amount cannot exceed $10 \mathrm{~mol} \%$.

Recently, we reported a novel doping strategy using two dopants simultaneously [25]. The nanostrain decreased significantly when BYNO (which has a lattice mismatch of 8.34\% with YBCO) and $\mathrm{LaAlO}_{3}$ (LAO) (which has a lattice mismatch of $-1.51 \%$ with YBCO) were added together with a YBCO film. The sample with 1.25 mol\% LAO 
and $7.5 \mathrm{~mol} \% \mathrm{BYNO}$ had $25 \%$ 30\% of strain as compared to the scenarios where LAO and BYNO were single doped. In this study, the double doping quantities of LAO and BYNO were systematically optimized, and the effects of LAO and BYNO in the double doping process were assessed.

\section{EXPERIMENT}

The precursor solutions for low-fluorine YBCO were prepared in four steps. First, acetylacetone of aluminum, acetylacetone of lanthanum, the acetates of yttrium, and the acetates of barium were dissolved in deionized water and then mixed with trifluoroacetic acid anhydride. The mixed solution was continually stirred for $2 \mathrm{~h}$ at $50{ }^{\circ} \mathrm{C}$ and evaporated to remove impurities, which were redissolved in methanol. Second, copper acetate was dissolved in deionized water and acrylic acid was poured stoichiometrically. The solution was continuously subject to reflux for $1 \mathrm{~h}$ at $80{ }^{\circ} \mathrm{C}$. Then, the solution was evaporated and redissolved as in the first step. Third, the solutions from the first two steps were mixed and evaporated thrice. Finally, niobium ethoxide was added drop-wise into the mixed solution in a glovebox under an Ar protective atmosphere, and the metered volume for the concentration of the cations of YBCO was maintained at $1.5 \mathrm{M}$. It is worth to point that we employ compensation method to prepare the solution, in other way, the amount of $\mathrm{Y}$ and $\mathrm{Ba}$ is excessed in the first step to compensate BYNO.

The precursor solution was deposited on a $5 \mathrm{~mm} \times 5 \mathrm{~mm}$ LAO single crystal by spin coating at $6000 \mathrm{rpm}$ for $60 \mathrm{~s}$. The heat treatment process was similar to those used in 
other studies [26]. Briefly, epitaxial films were grown at $830{ }^{\circ} \mathrm{C}$ for $90 \mathrm{~min}$ in a humid atmosphere and $30 \mathrm{~min}$ in a dry atmosphere (200-300 ppm of $\mathrm{O}_{2}$ in Ar). The superconducting phase was achieved by annealing at $450{ }^{\circ} \mathrm{C}$ for $3 \mathrm{~h}$ in an oxygen atmosphere.

The phase formation, the nanostrain in the $c$ direction, the $\phi$ scan curve, and the rocking scan curve were measured using X-ray diffraction (XRD), conducted using a Rigaku smart-lab diffractometer (Rigaku, Japan). Scanning electron microscopy (SEM) and energy-dispersive X-ray spectroscopy (EDS) were used to detect the microstructures. The superconducting properties were measured using a vibrating sample magnetometer (VSM). Magneto-optic microscopy (MO) was used to detect the pinning effect in the YBCO film.

\section{RESULTS}

Figure 1 shows the texture, strain, and $J_{\mathrm{c}}$ distribution of double-doped YBCO films with different quantities of LAO and BYNO. As the mismatch of BYNO (8.34\%) was much larger than that of LAO $(-1.51 \%)$, the strain of the single BYNO doping sample was much higher than that of the LAO sample, even with an equal amount of doping. It was observed that the $c$-strains of all the double doped samples were lower than the single doped samples. This indicated that the double doping of positive mismatch BYNO and negative mismatch LAO could indeed cancel the strains of each other. The $c$-strain for LAO between $0-5 \mathrm{~mol} \%$ and for BYNO between $1.25-7.5 \mathrm{~mol} \%$ was the lowest, as shown by the dark blue area in figure 1 (a). The lowest $c$-strain value 
was 0.026 , which is only one-third of the $7.5 \mathrm{~mol} \%$ single BYNO-doped sample (0.093).

Unlike the $c$-strain, the (005)-FWHM showed a lower value at the lower doping amount, as shown in figure 1 (b). It seems that the single-doped sample had a slightly worse out-of-plane orientation than the double-doped sample. The doping amount with double doping was also higher. However, the enhancement of double doping in the out-of-plane orientation was not as significant as that in the strain.

In the $J_{\mathrm{c}}$ distribution at $77 \mathrm{~K}$ with different applied fields, it was observed that the double doping significantly enhanced the $J_{\mathrm{c}}$ value as compared to the single-doped samples, as shown in figure 1 (c) - (f). This shows that the maximum $J_{\mathrm{c}}$ area overlaps with the low strain area, indicating that doping the positive mismatch dopant and negative mismatch dopant could cancel the strain and enhance the $J_{\mathrm{c}}$ of the YBCO film. With an increase in the applied field, the maximum area shrunk towards the high BYNO and low LAO direction. The best doping occurred at $1.25 \mathrm{~mol} \% \mathrm{LAO}+7.5$ mol\% BYNO, which also had the lowest c-strain value. 
(a)

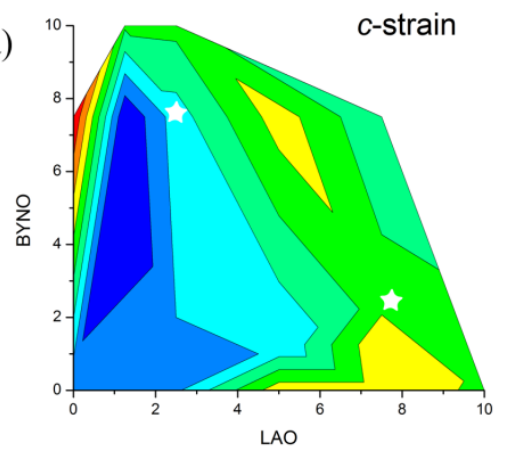

(c)

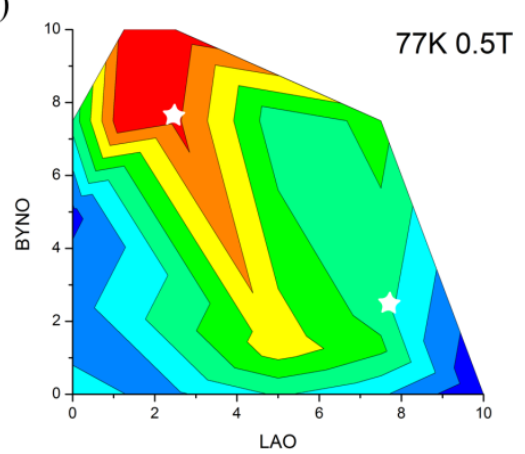

(e)

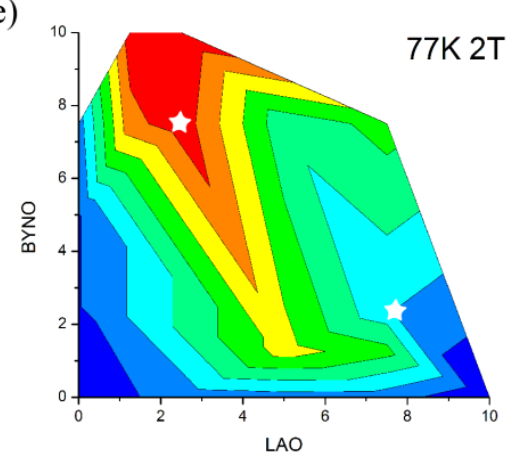

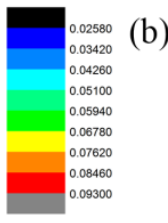

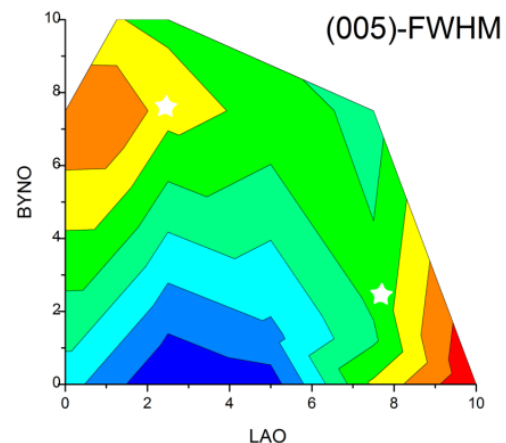

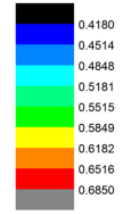

(d)
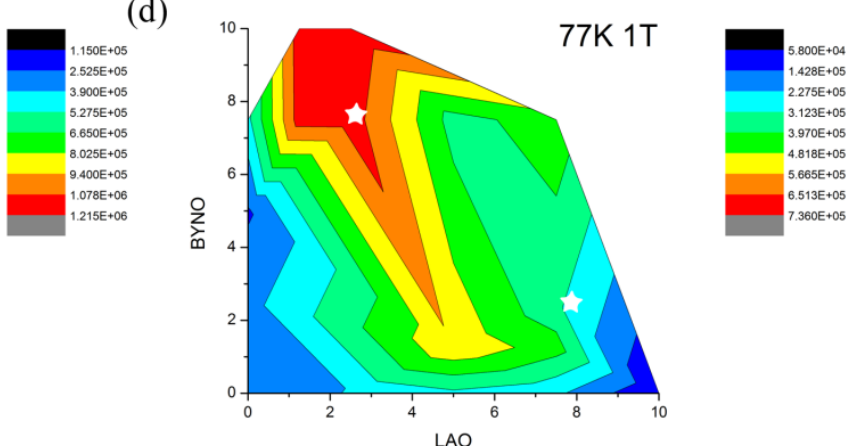

(f)

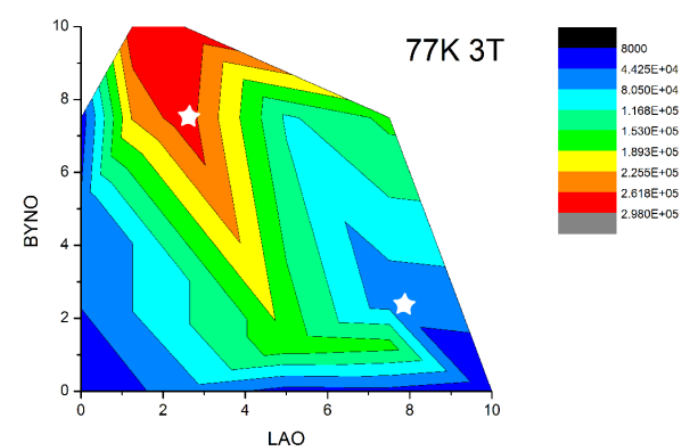

Figure 1 Distribution of (a) c-strain, (b) (005) FWHM, and $J_{\mathrm{c}}$ at $77 \mathrm{~K}$, (c) $0.5 \mathrm{~T}$, (d) 1 $\mathrm{T}$, (e) $2 \mathrm{~T}$, and (f) $3 \mathrm{~T}$ of the YBCO film with different amounts of LAO and BYNO. The white stars show the the sample of $2.5 \mathrm{~L}+7.5 \mathrm{~B}$ and $7.5 \mathrm{~L}+2.5 \mathrm{~B}$, which are discussed later.

Except for (005)-FWHM, none of the other figures showed any kind of symmetry, indicating that the low BYNO and high LAO are not equal to the high BYNO and low LAO. Therefore, it is worth further exploring the effect of BYNO and LAO in the 
double doping process. Two samples with a total doping amount of $10 \mathrm{~mol} \%$ were chosen: $7.5 \mathrm{~mol} \% \mathrm{LAO}+2.5 \mathrm{~mol} \% \mathrm{BYNO}$ and $2.5 \mathrm{~mol} \% \mathrm{LAO}+7.5 \mathrm{~mol} \% \mathrm{BYNO}$, referred to as $7.5 \mathrm{~L}+2.5 \mathrm{~B}$ and $2.5 \mathrm{~L}+7.5 \mathrm{~B}$, respectively.

Figure 2 shows the XRD results of the two samples. Both samples showed a strong YBCO c-orientation. The peak at $43.16^{\circ}$ corresponds to the BYNO phase. The peak intensity was higher in $2.5 \mathrm{~L}+7.5 \mathrm{~B}$. The $c$-strain, $\phi$ scan, and rocking scan values are shown in Table 1. It can be seen that both samples have very similar values of orientation and strain. It is worth mentioning that the $c$-strain in both samples was lower than the value of $10 \mathrm{~mol} \%$ single LAO or $7.5 \mathrm{~mol} \%$ BYNO, which indicates the canceling effect on the strain in both the double-doped samples.

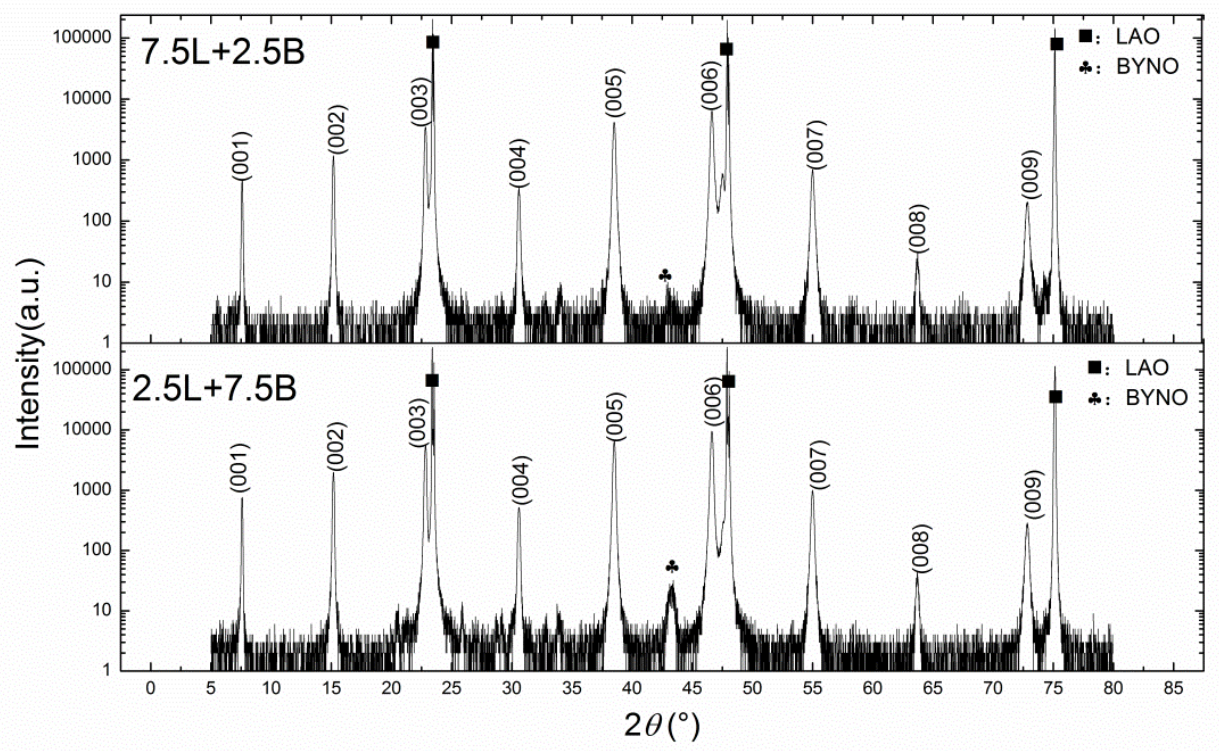

Figure 2 XRD patterns of the YBCO film with different doping amounts of LAO and BYNO. 
Figure 3 shows the SEM images of the two samples. The $2.5 \mathrm{~L}+7.5 \mathrm{~B}$ sample had a dense surface without visible a-axis grains. In contrast, the $7.5 \mathrm{~L}+2.5 \mathrm{~B}$ sample had many small particles and voids. Moreover, some long a-axis grains were observed on the surface, as shown in the red circles.

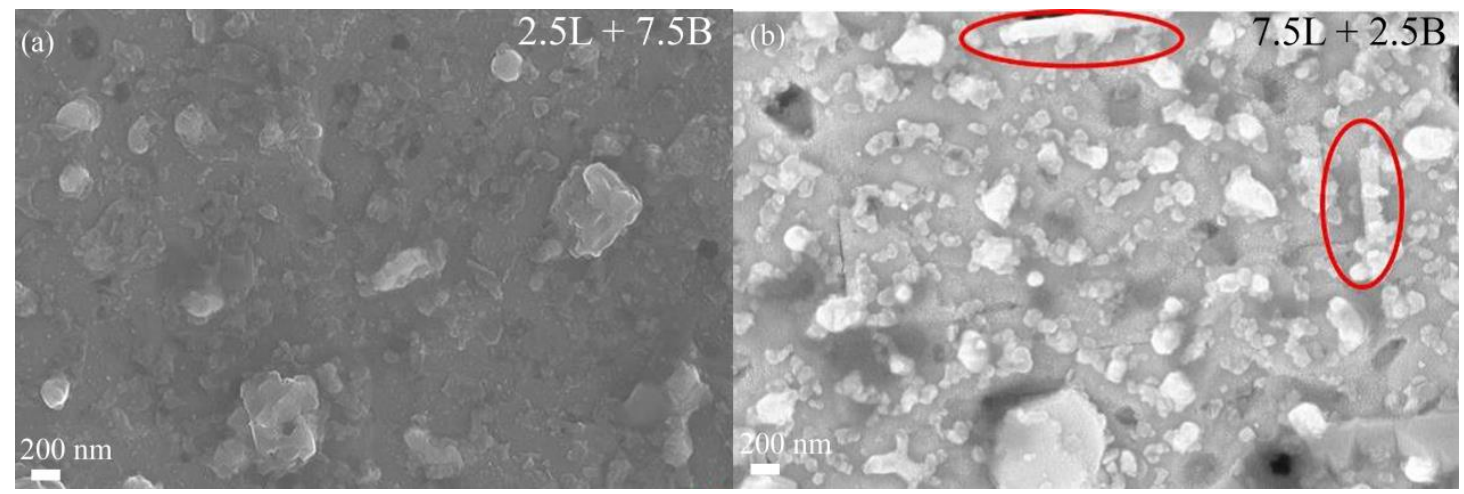

Figure 3 SEM images of the YBCO film with different doping amounts of LAO and BYNO: (a) 2.5L+7.5B and (b) 7.5L+2.5B.

Figure 4 and Table 1 show the superconducting properties of the two samples, which are marked as white star in figure 1. Both samples showed a sharp superconducting transition, as shown in figure 4 (a). Both $T_{\mathrm{c}}$ values were approximately $90 \mathrm{~K}$. This is consistent with the high-purity XRD results, which indicate that the high amount of double doping does not have a significant effect on the formation of the YBCO phase. The $J_{\mathrm{c}}$ value of the $2.5 \mathrm{~L}+7.5 \mathrm{~B}$ sample was higher than that of the $7.5 \mathrm{~L}+2.5 \mathrm{~B}$ sample at both $65 \mathrm{~K}$ and $77 \mathrm{~K}$ under all the applied fields. In particular, at $77 \mathrm{~K}$, the $J_{\mathrm{c}}$ curve of the $2.5 \mathrm{~L}+7.5 \mathrm{~B}$ sample had a lower slope as compared to the $7.5 \mathrm{~L}+2.5 \mathrm{~B}$ sample. As shown in Table 1 , the $J_{\mathrm{c}}$ value increased twice at $0.5 \mathrm{~T}$, but nearly a factor of five at 3 $\mathrm{T}$. The $2.5 \mathrm{~L}+7.5 \mathrm{~B}$ sample also showed an overwhelming pinning force, as shown in figure 4 (c). To investigate the pinning mechanism, the pinning force curves were 
fitted based on Ref. 27 and 28, as shown in figure 4 (d). Although the 2.5L+7.5B sample had a stronger pinning force, it had the same pinning mechanism as that of the 7.5L+2.5B sample, which consists of "normal surface pinning", such as the grain-, twin- and martensite boundaries, stacking faults, dislocation arrays such as sub-grain and polygonized boundaries, plate-like precipitates, and the surface of the superconductor [27]. It was observed that both samples had the same type of pinning center. Therefore, it can be deduced that the key to the excellent $J_{\mathrm{c}}$ value of the $2.5 \mathrm{~L}+7.5 \mathrm{~B}$ sample is an improved distribution of the pinning centers.
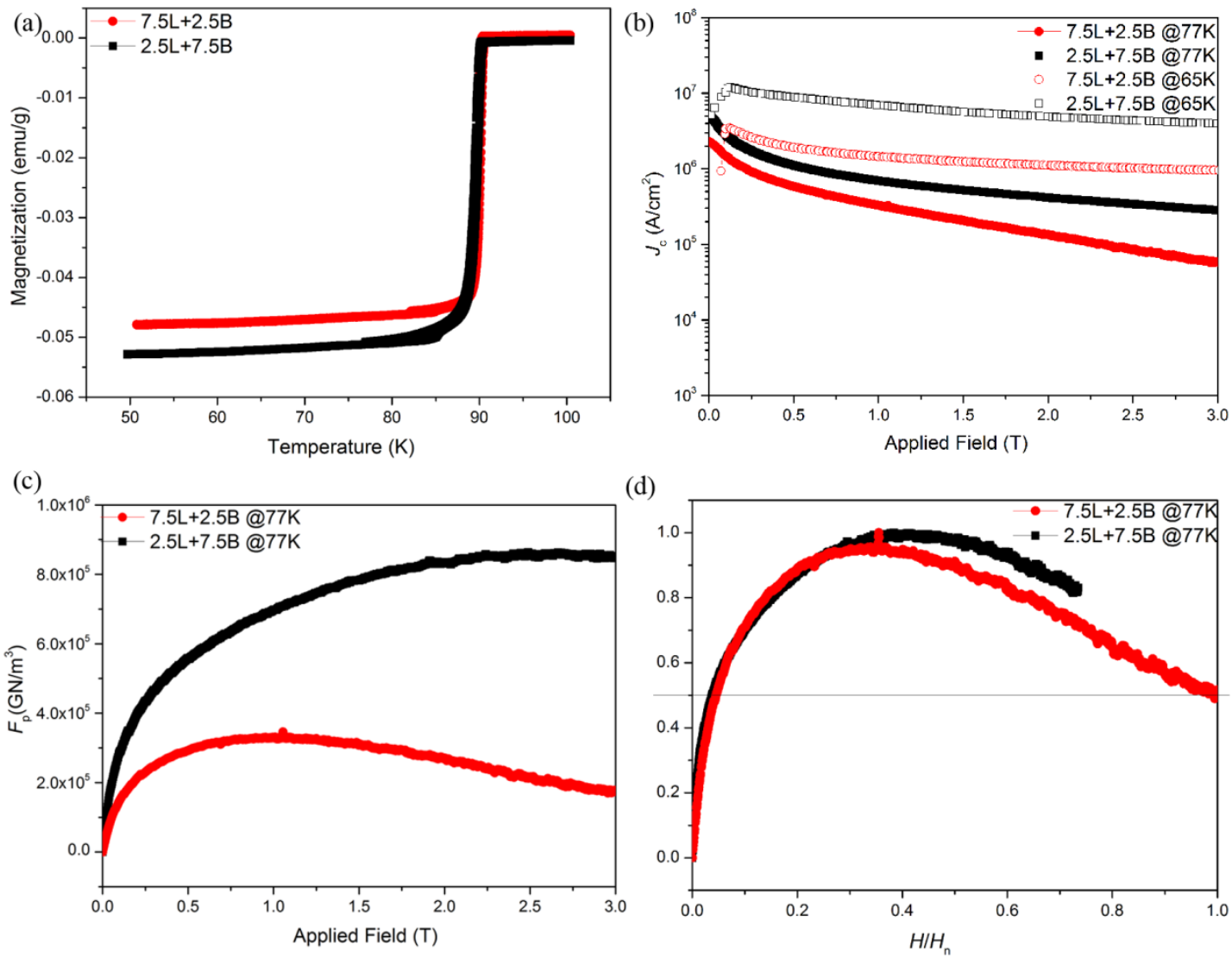

Figure 4 The superconducting properties of the YBCO film with different doping amounts of LAO and BYNO: (a) Zero-field-cooled curve, (b) $J_{\mathrm{c}}$ vs. field curve at 77 $\mathrm{K}$ and $65 \mathrm{~K}$, (c) $F_{\mathrm{p}}$ vs. field curve at $77 \mathrm{~K}$, and (d) $F_{p} / F_{\mathrm{p} \max }$ vs. $H / H_{\mathrm{n}}$ curve at $77 \mathrm{~K}$. 
Table 1 Orientation, strain results, and $T_{\mathrm{c}}$, and $J_{\mathrm{c}}$ values of the YBCO films with different amounts of LAO and BYNO dopants

\begin{tabular}{|c|c|c|c|c|c|c|}
\hline \multirow{2}{*}{ Sample } & \multirow{2}{*}{$\begin{array}{c}(103) \\
\text { FWHM }\end{array}$} & \multirow{2}{*}{$\begin{array}{c}(005) \\
\text { FWHM }\end{array}$} & \multirow{2}{*}{$c$-strain } & \multirow{2}{*}{$\begin{array}{c}T_{\mathrm{c}} \\
(\mathrm{K})\end{array}$} & \multicolumn{2}{|c|}{$\begin{array}{c}J_{\mathrm{c}}\left(\mathrm{MA} / \mathrm{cm}^{2}\right) \\
\text { at } 77 \mathrm{~K}\end{array}$} \\
\cline { 5 - 7 } & & & & $0.5 \mathrm{~T}$ & $3 \mathrm{~T}$ \\
\hline $7.5 \mathrm{~L}+2.5 \mathrm{~B}$ & 1.118 & 0.561 & 0.561 & 90.3 & 1.11 & 0.28 \\
\hline $2.5 \mathrm{~L}+7.5 \mathrm{~B}$ & 1.275 & 0.598 & 0.598 & 90.5 & 0.58 & 0.058 \\
\hline
\end{tabular}

To further explore the difference in the pinning centers between the two samples, MO was used. All the samples were zero-field cooled to $20 \mathrm{~K}$, and a field perpendicular to the plane of the film was added up to $85 \mathrm{mT}$. Then, the applied field was turned down to zero, as shown in figure 5. It was observed that in the $2.5 \mathrm{~L}+7.5 \mathrm{~B}$ sample, the flux only existed at the edge of the film and barely penetrated into the film at $17 \mathrm{mT}$. After $34 \mathrm{mT}$, the flux started to slowly penetrate into the film. However, it did not reach full penetration even at $85 \mathrm{mT}$. The flux penetration had a relevant symmetrical shape, and formed a classic shape at $85 \mathrm{mT}$. However, a few feather-like areas were observed at the right and bottom of the film, indicating the existence of relatively large defects in the film. In contrast, for the $7.5 \mathrm{~L}+2.5 \mathrm{~B}$ sample, the flux easily penetrated the film even at $17 \mathrm{mT}$, and the penetration area is completely closed at 68 $\mathrm{mT}$. The final shape was not symmetrical, and there was a significant additional area in the middle, indicating a large defect in this sample.

During the demagnetization process, magnetic flux of opposite direction enters the film from the edge cancelling the flux, which is already inside. In the $2.5 \mathrm{~L}+7.5 \mathrm{~B}$ sample, even when the applied field was reduced to zero, large bright areas remained 
in the middle of the sample, which demonstrates strong pinning preventing penetration of negative flux. On the other hand, the previously trapped flux in the $7.5 \mathrm{~L}+2.5 \mathrm{~B}$ sample only existed in an " $\mathrm{X}$ " shaped area at the diagonal of the film. This indicates that the sample barely trapped any flux during demagnetization. After demagnetization, both samples were heated, as evidenced by the bright area in figure 6. It was observed that the $7.5 \mathrm{~L}+2.5 \mathrm{~B}$ sample completely entered the normal state at $88 \mathrm{~K}$, while the $2.5 \mathrm{~L}+7.5 \mathrm{~B}$ sample still retained the superconducting state, as shown in the bright area in figure 6 . The $2.5 \mathrm{~L}+7.5 \mathrm{~B}$ sample did not lose the superconducting state even at $90 \mathrm{~K}$, as shown in figure S1. Although the VSM results showed that both samples have similar $T_{\mathrm{c}}$ about $90 \mathrm{~K}$, the MO results allow to emphasize the difference in their magnetic behavior close to this temperature.

The two samples had similar MO results at 5, 50, and $77 \mathrm{~K}$, as shown in figure $\mathrm{S} 2-$ S4. It can be concluded that the $2.5 \mathrm{~L}+7.5 \mathrm{~B}$ sample had a more robust and homogenous pinning than the $7.5 \mathrm{~L}+2.5 \mathrm{~B}$ sample, which proves our conclusion from the analysis of the pinning mechanism in figure $4(\mathrm{~d})$. 

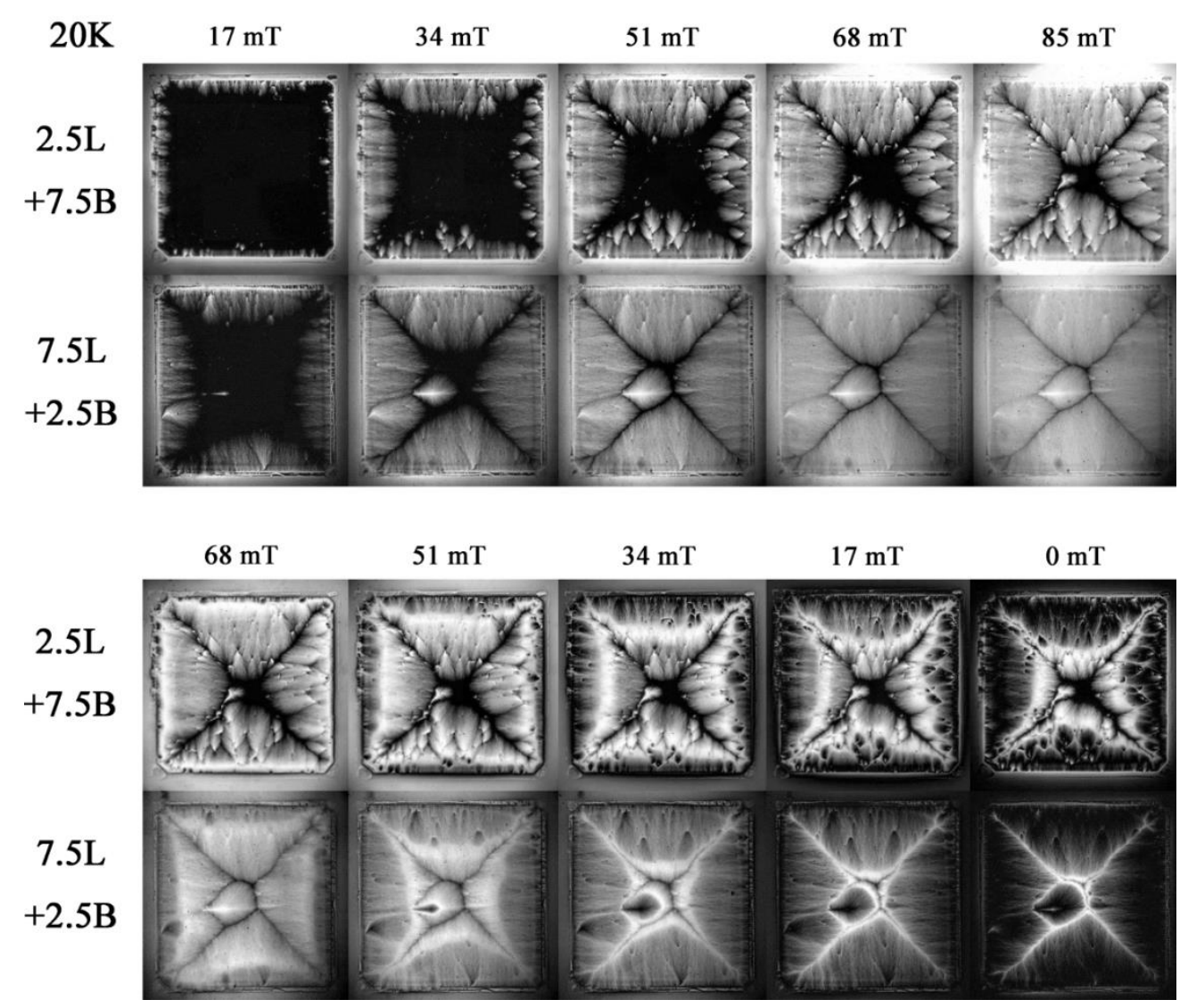

Figure $5 \mathrm{MO}$ images of the YBCO film with different doping amounts of LAO and BYNO at $20 \mathrm{~K}$.

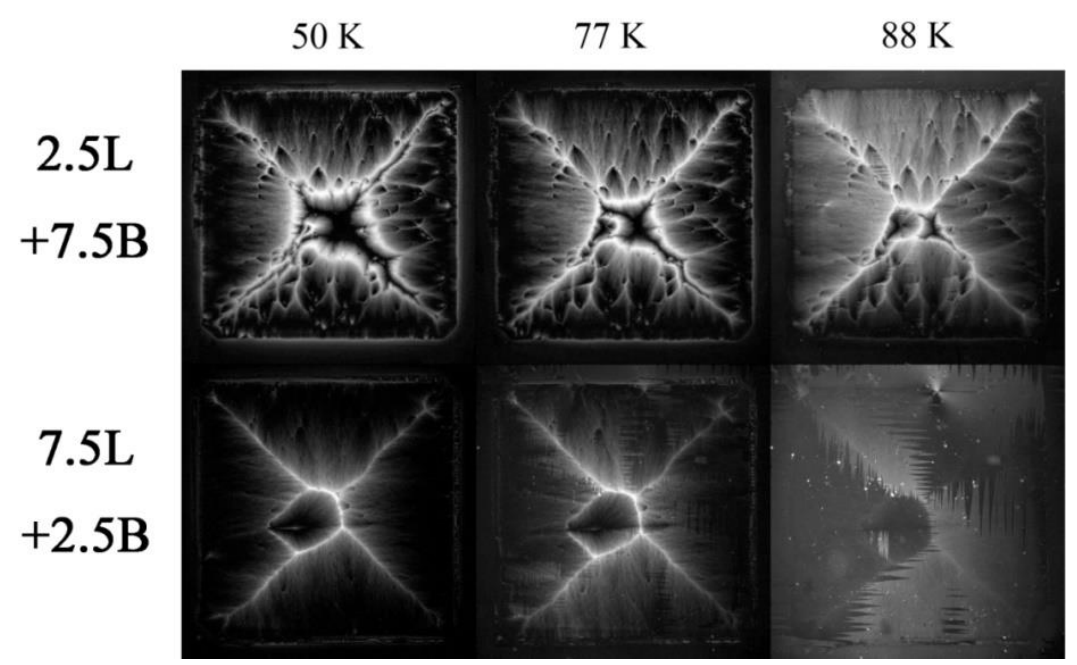

Figure $6 \mathrm{MO}$ images of the YBCO film with different doping amounts of LAO and BYNO. 
To get additional information about the pinning centers, a combination of MO and SEM was used. Figure 7 (a) and (b) are the MO images of both samples, that were field cooled to under $25.5 \mathrm{mT}$ to $5 \mathrm{~K}$, and then the applied field was removed. It can be seen that there are several feather-like dark areas in figure 7 (b) which are absent in (a), which indicate that the $2.5 \mathrm{~L}+7.5 \mathrm{~B}$ sample trapped the supercurrent much better than the 7.5L+2.5B sample. Small bright dots were observed in both MO images. The SEM images of one such dot in the $2.5 \mathrm{~L}+7.5 \mathrm{~B}$ sample are shown in figure 7 (c). Two mesh-like particles with sizes of approximately a few tens of micrometers can be observed. Around these mesh-like particles, the surface of the film is smooth and clean. In the area further away from the mesh-like particles, several nanodots can be observed. Analyzing the element distribution using EDS, it was confirmed that the mesh-like particles were LAO with a small amount of $\mathrm{CuO}$. The smooth and clean surface was pure YBCO, and the nanodots could be BYNO and LAO nanoparticles. Figure $7(\mathrm{e})-(\mathrm{g})$ show the field cooled MO images of the particles in figure 7 (c) at different fields. It was found that in the area around the mesh-like particles, the pinning effect was much lower than that of the surrounding area. Similar results were obtained for the $7.5 \mathrm{~L}+2.5 \mathrm{~B}$ sample, as shown in figure $\mathrm{S} 4$.

It was found that the LAO has a tendency to agglomerate into large mesh-like particles in our double-doped sample. Such tens of micrometer-sized LAO particles could not act as pinning centers and caused an apparent low pinning area. 


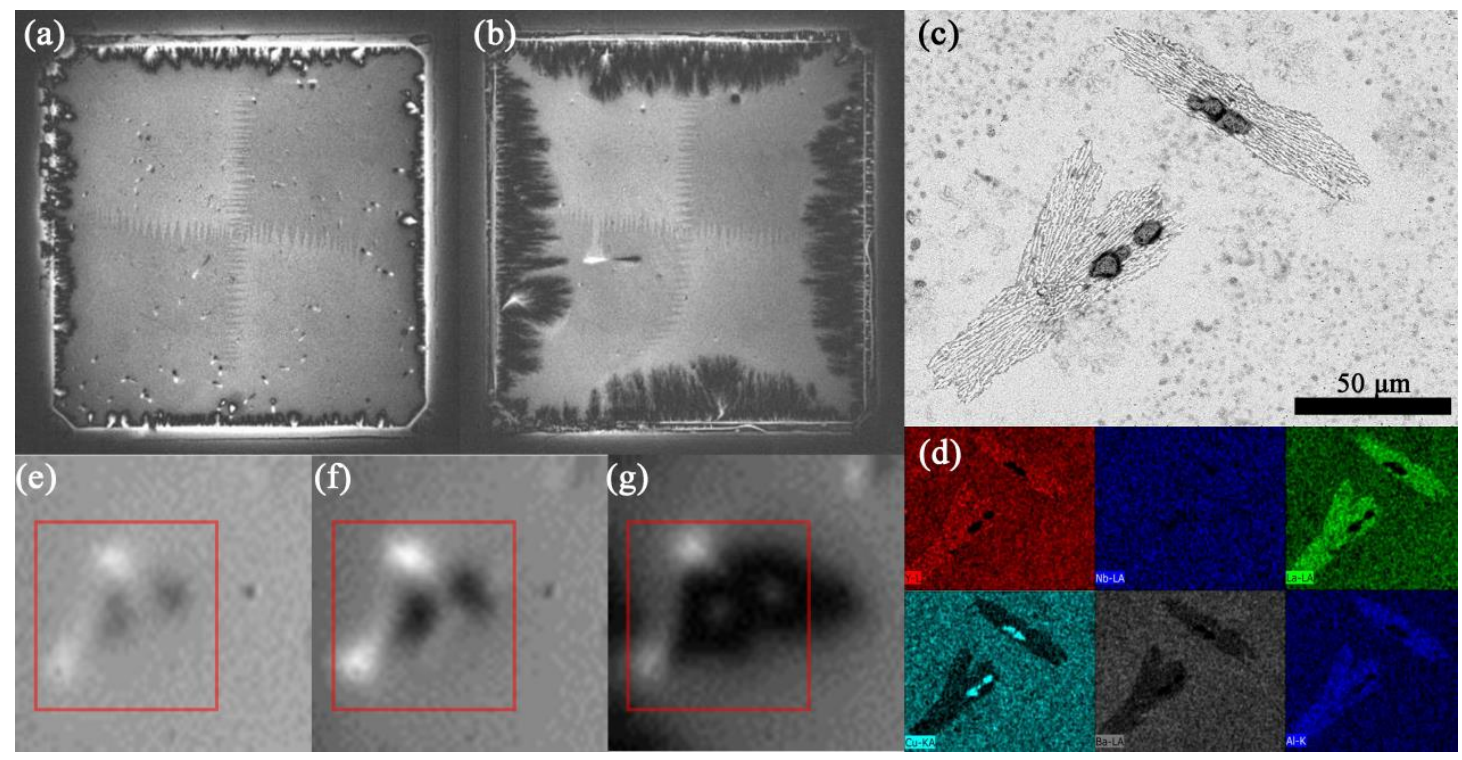

Figure $7 \mathrm{MO}$ images of the field cooled YBCO films; (a) $2.5 \mathrm{~L}+7.5 \mathrm{~B}$ and (b) 7.5L+2.5B. (c) SEM images of small dots in (a). (d) EDS scans of the area (c). Field cooled MO images of the area (c) in the 2.5L+7.5B sample at $17 \mathrm{mT}(\mathrm{e}), 8.5 \mathrm{mT}$ (f), and $0 \mathrm{mT}(\mathrm{g})$.

\section{DISCUSSION}

From the results shown above, it can be confirmed that our novel double doping strategy using both positive mismatch and negative mismatch dopants can significantly decrease the nanostrain and increase the superconducting properties of YBCO films. This can be used in two possible workflows. The first is to achieve the same $J_{\mathrm{c}}$ value using a lower doping amount. The best $J_{\mathrm{c}}$ value of single doping appears at $7.5 \mathrm{~mol} \%$ for either BYNO or LAO. However, as shown in figure 1, only 2 mol\% LAO $+2 \mathrm{~mol} \% \mathrm{BYNO}$ is required to obtain the same $J_{\mathrm{c}}$ value. At the same time, the c-strain is of the $2 \mathrm{~mol} \% \mathrm{LAO}+2 \mathrm{~mol} \% \mathrm{BYNO}$ phase is as low as that of the pure YBCO phase, which is significantly lower than that of $7.5 \mathrm{~mol} \%$ BYNO or LAO. Since the YBCO is usually used under high field and high current, a large Lorentz force is added to the YBCO film. The intrinsic strain in the film can cause a sequence crack under the server force. Therefore, our novel double doping strategy 
can prevent such cracks. The second option is to further improve the superconducting properties based on the current single doping. As shown in figure 1, the maximum of the double doping is twice as high as the maximum of single doping at $0.5 \mathrm{~T}$ and $77 \mathrm{~K}$, and is one order of magnitude higher at $3 \mathrm{~T}$ and $77 \mathrm{~K}$.

However, there are a few issues that need to be solved. The first is the choice of the dopant. To cancel the positive mismatch dopant and negative mismatch dopant, all the dopants should be nanoparticles and homogenously distributed in the YBCO film. According to our previous study [25], LAO can form nanoparticles. However, the current study shows that the LAO can form nanoparticles and large agglomerates at the same time. More importantly, the large agglomerates increase with an increase in the LAO doping amount. It seems that LAO may not be the best choice for the negative mismatch dopant. However, $\mathrm{Y}_{2} \mathrm{O}_{3}$, which has a $-3.3 \%$ mismatch with $\mathrm{YBCO}$, could be a suitable choice.

\section{CONCLUSION}

In this study, we systematically optimized the doping amount of the positive mismatch dopant BYNO and the negative mismatch dopant LAO. It was found that double doping can significantly decrease the $c$-strain and increase the $J_{c}$ value, especially at high applied fields. At $77 \mathrm{~K}$ and $3 \mathrm{~T}$, the maximum of the double doped sample was one order of magnitude higher than the maximum of each individual single doped sample. It was found that BYNO and LAO did not have similar roles in the double doping process. The LAO has a tendency to agglomerate into mesh-like particles with a size of tens of micrometers. The MO results showed that around such mesh-like particles, the pinning is significantly weaker than that in other areas. It can be concluded that the mismatch value is not the only standard for choosing the dopant. In summary, the double doping strategy is a feasible and promising way to further improve the superconducting properties of YBCO films by choosing appropriate dopants. 


\section{SUPPLEMENTARY MATERIALS}

See supplementary materials for the following information

Figure S1: The MO images of the 2.5L+7.5B sample at $90 \mathrm{~K}$; Figure S2 The MO images of the two sample at $5 \mathrm{~K}$; Figure S3 The MO images of the two sample at 50 K; Figure S3 The MO images of the two sample at $50 \mathrm{~K}$; Figure S4 The SEM images and EDS results of the small particles in the 7.5L+2.5B sample

\section{ACKNOWLEDGMENTS}

This paper was supported by the This work is funded by the National Natural Science Foundation of China (51702316, 51807191 and 11745005), the General Program of Science and Technology Development Project of Beijing Municipal Education Commission of China (KM201810005010), 211 Program of Beijing City and Beijing University of Technology, and the Program of Top Disciplines Construction in Beijing (PXM2019_014204_500031) and the International Partnership Program of the Chinese Academy of Sciences (182111KYSB20170039 and 182111KYSB20170067), Key Research Program of Frontier Sciences, CAS, (ZDBS-LY- JSC039)

\section{REFERENCE}

[1] X. Chen, S.J. Zheng, J. Li, G.T. Ma, F. Yen, A linear induction motor with a coated conductor superconducting secondary Physica C (550) 2018, 82-84 DOI:

10.1016/j.physc.2018.04.002

[2] A. Bergen, R. Andersen, M. Bauer, H. Boy, M. ter Brake, P. Brutsaert, C. Buhrer,

M. Dhalle, J. Hansen, H. ten Kate, J. Kellers, J. Krause, E. Krooshoop, C. Kruse, H.

Kylling, M Pilas, H. Putz, A. Rebsdorf, M. Reckhard, E. Seitz, H. Springer, X.W.

Song, N. Tzabar, S. Wessel, J. Wiezoreck, T. Winkler, K. Yagotyntsev. Design and 
in-field testing of the world's first ReBCO rotor for a 3.6 MW wind generator Superconductor Science \& Technology (32) (12) 2019, 125006 DOI:

$10.1088 / 1361-6668 / a b 48 d 6$

[3] P. Gao, M. Dhalle, B. van Nugteren, H. Norder, A. Kario, S. Otten, W. Goldacker, J. van Nugteren, G. Kirby, G. de Rijk, L. Bottura, L. Rossi, H.H.J. ten Kate.

Inter-strand resistance and $\mathrm{AC}$ loss in resin-filler impregnated ReBCO Roebel cables Superconductor Science \& Technology (32) (2) 2019, 125002 DOI: $10.1088 / 1361-6668 / a b 4665$

[4] J.H. Zhu, P.P. Chen, M. Qiu, C.Q. Liu, J.L. Liu, H.M. Zhang, H.J. Zhang, K.Z. Ding. Experimental Investigation of a High Temperature Superconducting Pancake Consisted of the REBCO Composite Cable for Superconducting Magnetic Energy Storage System IEEE Transactions on Applied Superconductivity (29) (5) 2019, 5700704 DOI: 10.1109/TASC.2019.2897574

[5] M. Buran, M. Vojenciak, M. Mosat, A. Ghabeli, M. Solovyov, M. Pekarcikova, L. Kopera, F. Gomory. Impact of a REBCO coated conductor stabilization layer on the fault current limiting functionality Superconductor Science \& Technology (32) (9) 2019, 095008 DOI: 10.1088/1361-6668/ab2c8e

[6] M.Y. Li, X.Y. Chen, H.Y. Gou, Y. Chen, Q. Xie, M.G. Tang, Q. Xu, Q Conceptual Design and Characteristic Analysis of a Sliding-Type Superconducting Wireless Power Transfer System Using ReBCO Primary at 50 
Hz IEEE Transactions on Applied Superconductivity (29) (2) 2019, 5501304 DOI:

10.1109/TASC.2019.2894444

[7] A. Zappatore, R. Heller, L. Savoldi, R. Zanino, Assessment of the performance of a 20 kA REBCO current lead Cryogenics (95) 2018, 95-101 DOI:

10.1016/j.cryogenics.2018.09.003

[8] Y. Suetomi, $30 \mathrm{~T}$ generation using an intra-layer no-insulation (LNI) REBCO coil in a 17 T LTS magnet”, Fri-Mo-Or27-02 MT26, 2018

[9] S. Yoon, J. Kim, K. Cheon, H. Lee, S. Hahn, and S. H. Moon, 26-T 35-mm

all-REBCO multi-width no-insulation superconducting magnet, Superconductor Science \& Technology (29) 2016, 04LT04, 2016 DOI:

10.1088/0953-2048/29/4/04LT04

[10]https://nationalmaglab.org/news-events/news/new-world-record-magnet-fulfills-s uperconducting-promise

[11] J.H. Liu, Q.L. Wang, L. Qin, B.Z. Zhou, K.S. Wang, Y.H. Wang, L. Wang, Z.L. Zhang, Y.M. Dai, H. Liu, X.N. Hu, H. Wang, C.Y. Cui, D.G. Wang, H. Wang, J.S. Sun, W.S. Sun, L. Xiong World record 32.35tesla direct-current magnetic field generated with an all-superconducting magnet Superconductor Science \& Technology (33) 2020, 03LT01 DOI: 10.1088/1361-6668/ab714e

[12] J.Y. Chu, Y. Zhao, M.Z. Khan, X. Tang, W. Wu, J.T. Shi, Y. Wu, H. Huhtinen, H.L. Suo, Z.J. Jin. Insight into the Interfacial Nucleation and Competitive Growth 
of YBa2Cu3O7-delta Films as High-Performance Coated Conductors by a Fluorine-Free Metal-Organic Decomposition Route. Crystal Growth Design (19) 2019, 6752-6762 DOI: 10.1021/acs.cgd.9b01120

[13] S.R. Foltyn, L. Civale, J.L. Macmanus-Driscoll, Q.X. Jia, B. Maiorov, H. Wang, M. Maley. Materials science challenges for high-temperature superconducting wire Nature Materials (6) 2007, 631-642 DOI: 10.1038/nmat1989

[14] Y. Zhao, J.M. Zhu, G.Y. Jiang, C.S. Chen, W. Wu, Z.W. Zhang, S.K. Chen, Y.M. Hong, Z.Y. Hong, Z.J. Jin, Y. Yamada. Progress of second generation high temperature superconducting tape fabrication at Shanghai superconductor technology. Superconductor Science \& Technology (32) 2019, 044004 DOI: 10.1088/1361-6668/aafea5

[15] J.Y. Chu, Y. Zhao, L.F. Liu, W. Wu, Z.W. Zhang, Z.Y. Hong, Y.J. Li, Z.J. Jin. Topography evolution of rough-surface metallic substrates by solution deposition planarization method. Applied Surface Science (427) 2018, 237-242 DOI: 10.1016/j.apsusc.2017.08.161

[16] J.L. MacManus-Driscoll, M. Bianchetti, A. Kursumovic, G. Kim, W. Jo, H. Wang, J.H. Lee, G.W. Hong, S.H. Moon. Strong pinning in very fast grown reactive co-evaporated GdBa2Cu3O7 coated conductors. APL Materials (2) 2014, 086103 DOI: $10.1063 / 1.4893339$ 
[17] A. Xu, L. Delgado, N. Khatri, Y. Liu, V. Selvamanickam, D. Abraimov, J. Jaroszynski, F. Kametani, D.C. Larbalestier. Strongly enhanced vortex pinning from 4 to $77 \mathrm{~K}$ in magnetic fields up to $31 \mathrm{~T}$ in $15 \mathrm{~mol} . \% \mathrm{Zr}$-added (Gd, Y)-Ba-Cu-O superconducting tapes. APL Materials (2) 2014, 046111. DOI: $10.1063 / 1.4872060$

[18] S. Awaji, Y. Yoshida, T. Suzuki, K. Watanabe, K. Hikawa, Y. Ichino, T. Izumi. High-performance irreversibility field and flux pinning force density in BaHfO3-doped GdBa2Cu3Oy tape prepared by pulsed laser deposition. Applied Physics Express (8) 2015, 023101 DOI: 10.7567/APEX.8.023101

[19] S. Miura, Y. Yoshida, Y. Ichino, Q. Xu, K. Matsumoto, A. Ichinose, S. Awaji. Improvement in $\mathrm{J}(\mathrm{c})$ performance below liquid nitrogen temperature for SmBa2Cu3Oy superconducting films with BaHfO3 nano-rods controlled by low-temperature growth. APL Materials (4) 2016, 016102. DOI:

$10.1063 / 1.4939182$

[20] C.V. Varanasi, P.N. Barnes, J. Burke, L. Brunke, I. Maartense, T.J. Haugan, E.A. Stinzianni, K.A. Dunn, P. Haldar. Flux pinning enhancement in YBa2Cu3O7-x films with BaSnO3 nanoparticles. Superconductor Science \& Technology (19) 2006, L37-L41. DOI: 10.1088/0953-2048/19/10/L01

[21] G. Ercolano, S.A. Harrington, H. Wang, C.F. Tsai, J.L. MacManus-Driscoll. Enhanced flux pinning in YBa2Cu3O7-delta thin films using Nb-based double 
perovskite additions. Superconductor Science \& Technology (23) 2010, 022003.

DOI: $10.1088 / 0953-2048 / 23 / 2 / 022003$

[22] S.H. Wee, A. Goyal, E.D. Specht, C. Cantoni, Y.L. Zuev, V. Selvamanickam, S.

Cook. Enhanced flux pinning and critical current density via incorporation of self-assembled rare-earth barium tantalate nanocolumns within

YBa2Cu3O7-delta films. Physics Review B (81) 2010, 140503. DOI:

10.1103/PhysRevB.81.140503

[23] F. Rizzo, A. Augieri, A.A. Armenio, V. Galluzzi, A. Mancini, V. Pinto, A.

Rufoloni, A. Vannozzi, M. Bianchetti, A. Kursumovic, J.L. MacManus-Driscoll, A.

Meledin, G. Van Tendeloo, G. Celentano. Enhanced 77 K vortex-pinning in

YBa2Cu3O7-x films with Ba2YTaO6 and mixed Ba2YTaO6 + Ba2YNbO6

nano-columnar inclusions with irreversibility field to 11 T. APL Materials (4)

2016, 061101. DOI: 10.1063/1.4953436

[24] J.P.F. Feighan, A. Kursumovic, J.L. MacManus-Driscoll. Materials design for artificial pinning centers in superconductor PLD coated conductors.

Superconductor Science \& Technology (30) 2017, 123001. DOI:

10.1088/1361-6668/aa90d1

[25] Y. Xu, H.L. Suo, J-C. Grivel, M. Liu, X.L. Zhang, Y.Q. Zhou, J.H. Liu, Z.L.

Zhang. Synergistic Effects on the Nanostrain in YBCO Films Double-Doped with

Positive Mismatch Perovskite (Ba2YNbO6) and Negative Mismatch Perovskite

(LaAlO3) Crystal Growth Design 2020 DOI: 10.1021/acs.cgd.0c00227 
[26] X. Tang, Y. Zhao, W. Wu, J-C Grivel. Effect of BaZrO3/Ag hybrid doping to the microstructure and performance of fluorine-free MOD method derived YBa2Cu3O7-x superconducting thin films. J. Materials Science, (26) 2015, 1806-1811. DOI: 10.1007/s10854-014-2614-7

[27] D. Dew-Hugh Flux pinning mechanisms in type I1 superconductors. Philosophical Magazine (30) 1974, 293-305. DOI: 10.1080/14786439808206556 [28] M. Eisterer. Calculation of the volume pinning force in $\operatorname{MgB}(2)$ superconductors. Physic Review B (77) 2008, 144524. DOI: 10.1103/PhysRevB.77.144524 